\title{
El Bileğinde Ekstansiyon Kontraktürü Olan Yirmi Yıllık Bir Vakanin Tedavisi
}

\section{Treatment of a Twenty-Year Case with Extension Contracture of The Wrist}

Rafet Özbey ${ }^{1}$,

${ }^{1}$ Malatya Eğitim ve Araştırma Hastanesi, Plastik Cerrahi Kliniği, Malatya, Türkiye

Geliş Tarihi/Received: 10 January 2020 Kabul Tarihi/Accepted: 20 February 2020

Yazışma Adresi: Rafet Özbey, Malatya Eğitim ve Araştırma Hastanesi, Plastik Cerrahi Kliniği, Malatya, Türkiye

e-mail: rafetozbey@gmail.com

ORCID

Rafet Özbey

https://orcid.org/0000-0003-0759-5003

\section{Öz}

Üst ekstremitede yanık sonrası gelişen kontraktürler elin ve kolun fonksiyonunu kısıtlamaktadır. Bu raporda yanık sonrası üst ekstremite kontraktürü olan bir hastanın cerrahi tedavisini sunduk. Yirmibeş yaşında bayan hasta 3 yaşından beri sol el bileği bölgesindeki kontraktür sebebiyle polikliniğimize başvurdu. Muayenesinde hastanın sol elbilek ekstansör yüzde yaklaşık 120 derece ekstansiyon kontraktürü vardı. Hastanın kontraktürü yapılan insizyonla açılarak oluşan defekt karın flebiyle kapatıldı. Karın flebinin yanık sonrası görülen kontraktürlerin tedavisinde iyi bir tedavi alternatifi olduğunu düşünmekteyiz.

Anahtar Kelimeler: Kontraktür, yanık, karın flebi, el bilek kontraktürü.

\section{Abstract}

Postburn contractures in the upper extremities limit the function of the hand and arm. In this report, we presented surgical treatment of a patient with post burn contracture in the upper extremity. A 25-year-old female patient was admitted to our outpatient clinic for contracture of the left wrist since the age of three. On examination, the patient had an extension contracture of approximately 120 degrees in the left wrist. The patient's contracture was opened with an incision and the defect was closed with an abdominal flap. We think that abdominal flap is a good alternative for the treatment of postburn contractures.

Key words: Contracture, burn, abdominal flap, wrist contracture.
Atıf yapmak için: Özbey R. El Bileğinde Ekstansiyon Kontraktürü Olan Yirmi Yıllık Bir Vakanin Tedavisi. Selcuk Med J 2021;37(1): 77-79
Açıklama: Yazar bu makalede bahsedilen herhangi bir ürün, aygıt veya ilaç ile ilgili maddi çıkar ilişkisine sahip değildir. Araştırma, herhangi bir dış organizasyon tarafından desteklenmedi. Yazar çalışmanın birincil verilerine tam erişim izni vermek ve derginin talep ettiği takdirde verileri incelemesine izin vermeyi kabul etmektedir. 


\section{Gíniş}

Üstekstremitedeyanık sonrası gelişen kontraktürler elin ve kolun fonksiyonunu kısıtlamaktadır. Yanık sonrası kontraktür gelişimini önlemek amacıyla masaj, splint, bası tedavisi ve rehabilitasyon gibi birçok yöntem tarif edilmiştir. Bunlara rağmen kontraktürler yanık hastalarında hala önemli bir sorundur. Genellikle fleksiyon kontraktürleri olarak karşımıza çıkarlar. Kontraktürleri açmak için tekli ve çoklu z plastiler, deri grefti ve flepler kullanılabilir. Flepler lokal, bölgesel veya uzak flepler şeklinde olabilir. Yanıkta erken dönemde oluşan kontraktürler deri greftleriyle de tedavi edilebilir. Bununla beraber kronik dönemde kontraktürlerin açılması tendon, damar sinir gibi yapıların ortaya çıkmasına neden olduğundan flep kullanımı gerekmektedir. Tendon ve nörovasküler demet gibi yapılara daha elastik ve kalın bir örtü sağlaması, daha az kontraktüre uğraması gibi nedenlerle flep kullanımı önerilmektedir (1). Ekstansiyon kontraktürleri literatürde nispeten az göründüğü için karın flebi ile başarılı bir şekilde tedavi ettiğimiz bu olguyu sunmayı uygun gördük.

\section{OLGU}

Yirmibeş yaşında bayan hasta 3 yaşındayken sol eline sıcak su dökülmesi sonucu oluşan yanık ve buna sekonder gelişen kontraktüre bağlı sol elde hareket kısıtlılı̆ı ve deride çekme şikayetleriyle Hatay Antakya Devlet Hastanesi Plastik Cerrahi Polikliniğine başvurdu. Yanığın hastaneye gitmeden tedavi edildiğini ve sonrasında elde bu problemin olduğunu ifade etti. Suriyedeki savaştan kaçarak gelen hasta daha önce maddi sıkıntılar nedeniyle herhangi bir tedavi görmemiş. Günlük hayattta elini rahat kullanamadığını ve kötü görünen bu elin kendini sosyal açıdan zora soktuğu, bu sebeple kendini toplumdan izole ettiğini belirtti. Yapılan muayenede hastanın sol elbilek ekstansör yüzde yaklaşık 120 derece ekstansiyon kontraktürü vardı (Şekil 1). Hasta genel anestezi altında operasyona alındı. Sol elbileği eklemi dorsalinde horizontal olarak yapılan insizyonla cilt kontraktürü açıldı. Aşırı gergin olan ECR tendonu kesilerek kontraktürün tam olarak açılması sağlandı. Oluşan defekt karın flebiyle kapatıldı. Günlük yapılan yara bakımlarının ardından 3 hafta sonra flep karından ayrıldı. Takiplerinde komplikasyona rastlanmadı.

Postop 15. günde rehabilitasyona başlandı. Erken dönemlerde parmaklarda fleksiyon kısıtııı̆ı olmakla beraber ilerleyen haftalarda kavrama hareketini tama yakın yapıyordu. Flebin bulky problemi için hastaya inceltme önerildi. Hasta görünümden memnun

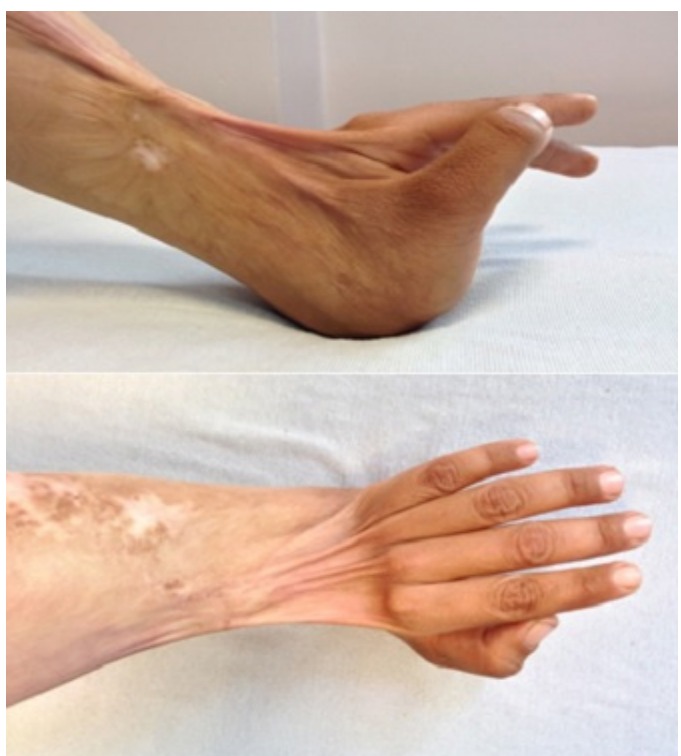

Şekil 1. El bileğinde belirgin ekstansiyon kontraktürü

olduğunu ifade edip ameliyatı kabul etmedi (Şekil 2).

\section{TARTIŞMA}

Yanık yaralanması tedavi dönemi uzun ve zor bir süreçtir. Yanık yarasının kapanmasıyla bu sürecin birkısmı geride bırakılmış olur. Yanık skarı ve

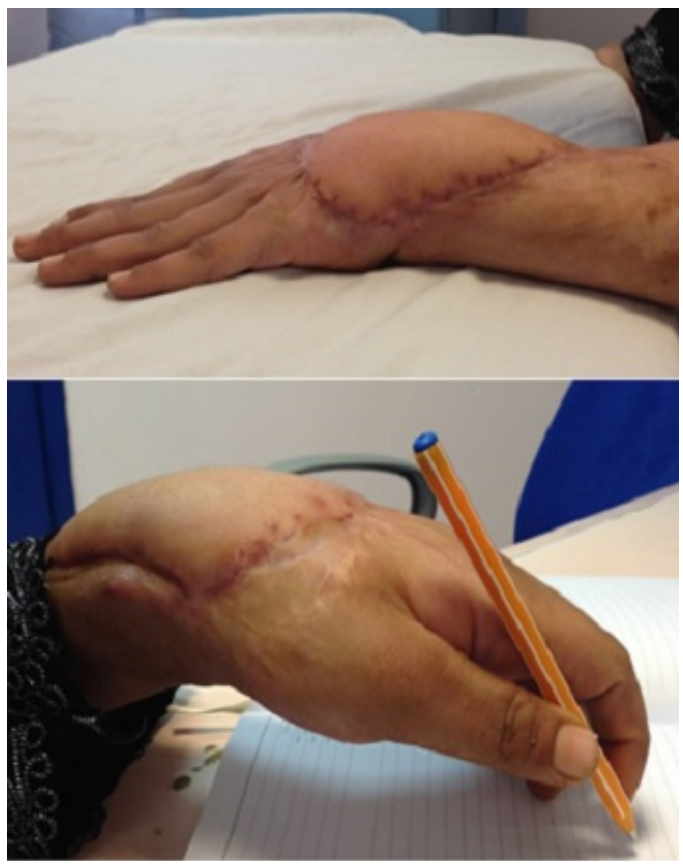

Şekil 2. Ameliyat sonrası kontraktürde belirgin düzelme 
kontraktürleri gibi komplikasyonlarla geri kalan kısmı devam etmektedir. Bunların önlenmesi ve tedavisinde erken dönemde yapılan splintleme, rehabilitasyon, lokal preparatlar, bası tedavisi ve masaj gibi yöntemler kullanılmakla beraber birçok yanık hastasında günlük yaşam aktivitelerini kısıtlayan önemli bir problem olarak varlığını devam ettirmektedir (2). Yapılan bir çalışmada yanık kontraktürlerinin esas sebebinin erken dönemde bu vakaların yanlış yönetimi ve yetersiz terapi olduğu bildirilmektedir (3). Genellikle fleksiyon kontraktürleri karşımıza çıkmakla beraber vakamızda ekstansiyon kontraktürü vardı (4).

Hafif kontraktürlerin tedavisinde tekli veya çoklu z plastiler yeterli olmaktadır. Orta ve ağır seviyelerde ise ilk aşama kontrakte olan tüm yapıların serbestleştirilmesidir. Derinin açılması tek başına yeterli olmamakta özellikle kronik dönemdeki bir kontraktürde nörovasküler yapılar, ligamanlar ve tendon kılıfları da etkilendiğinden bunları da kapsayan etkili bir serbestleştirme yapılmalıdır. Bunu yaparken nörovasküler yapıları gerecek kadar aşırı bir serbestleştirmeden kaçınılmalıdır. Yapılacak aşırı serbestleştirmelerin parmaklarda tromboz, iskemi ve hatta dolaşımın tamamen durmasına yol açabileceğini belirtilmiştir (5). İkinci aşama açılan kontraktürde oluşan doku defektini kapatmaktır. Bunun için deri greftleri ve flepler kulanılmaktadır. Deri greftleri defekt kapatmada geniş alanları kapatabilmesi ve rahat uygulanabilir olması nedeniyle iyi bir seçenek gibi görünse de fleplerin daha az kontrakte olması ve açığa çıkan tendon, sinir ve damar gibi yapılar için uygun kalitede elastik bir örtü oluşturması gibi nedenler flep kullanımını gerekli kılmaktadır. Flepler lokal, bölgesel olabileceği gibi uzak flepler de olabilmektedir (6-8).

Uzun dönemde, rekonstrüksiyon gereken yanıklı bir üst ekstremitede elde lokal flep alanları çoğu kez skar dokusu ile kaplı olması lokal flep kullanımını kısıtlamaktadır (9). Eldeki örtü problemlerin çözümünde mikrovasküler doku aktarımları da iyi bir seçenektir. Ancak bu konuda deneyimli bir ekip ve teknik donanım gerektirmeleri ve ameliyat süresinin uzun oluşu bu ameliyatların dezavantajları arasındadır

Toraks ve abdomenden kaldırılan iki aşamalı flepler de bu bölge defektleri için kullanım seçenekleri arasındadır. Ancak hastanın 2 kez ameliyat olması, 3 hafta üst ekstremitenin immobilizasyon zorunluluğu ve flepte bulky problemleri bu tür fleplerin kullanılabilirliğini sınırlar (10). Bununla beraber kolay öğrenilebilir ve güvenli olması avantajlarıdır. Biz vakamızda kontraktür açılmasını takiben defekti kapatmak için bu flebi kullandık. Kontraktür açılması sonrası açığa çıkan tendon gibi yapılara esnek ve kaliteli bir örtü sağladı.

Erken dönemde doğru şekilde yapılan yanık yönetimi ve terapiyle kontraktürlerin büyük kısmının oluşması engellenebilir. Çocukluk döneminde olan yanıklar sonucu meydana gelen kontraktürlerde tendonlarda oluşan kontraktürü açmadan yeterli bir serbestleştirme yapılamamaktadır. Gerekli durumlarda tenoplasti ve tenotomi yapmaktan çekinilmemelidir. Kontraktür cerrahisi sonrası açığa çıkan tendon ve nörovasküler yapılara yeterli bir destek sağlayan, uygulanımı kolay ve güvenli bir seçenek olan karın flebinin yanık sonrası görülen kontraktürlerin tedavisinde iyi bir tedavi alternatifi olduğunu düşünmekteyiz.

Çıkar Çatışması: Çalışmada herhangi bir çıkar çatışması yoktur.

Finansal Çıkar Çatışması: Çalışmada herhangi bir finansal çıkar çatışması yoktur.

Yazışma Adresi: Rafet Özbey, Malatya Eğitim ve Araştırma Hastanesi, Plastik Cerrahi Kliniği, Malatya, Türkiye

Telefon: +905055790500

e-mail: rafetozbey@gmail.com

\section{KAYNAKLAR}

1. Açıkel C, Ülkür E, Bayram İ, et al. El parmaklarında yanığa bağlı gelişen kronik fleksiyon kontraktürlerinin üçlü laterodigital fleplerle tedavisi. Türk Plastik, Rekonstrüktif ve Estetik Cerrahi Dergisi 2003;11(1):22-6.

2. Okur MI, Yildirim AM, Ince B. The utility of onion extract gel containing topical allantoin and heparin after surgical treatment of upper extremity burn scars. Hand Microsurg 2014;3(3):74-9.

3. Serghiou M, Cowan A, Whitehead C. Rehabilitation after a burn injury. Clin Plast Surg 2009;36(4):675-86.

4. Gümüş N. Difficulties with running $V-Y$ plasty in releasing burn scar contracture. Ulus Travma Acil Cerrahi Derg 2010;16(5):407-12.

5. Jackson IT, Brown GED. A method of treating chronic fîexion contractures of the fingers. Brit J Plast Surg 1970;23:373

6. Acikel C, Peker F, Yuksel F, et al. Bilateral side finger transposition flaps in the treatment of chronic postburn flexion contractures of the fingers. Ann Plast Surg 2002;49(4):344-9.

7. Schwarz RJ. Management of postburn contractures of the upper extremity. J Burn Care Res 2007;28(2):212-9.

8. Hudson DA, Renshaw A. An algorithm for the release of burn contractures of the extremities. Burns 2006;32(6):663-8.

9. Bozdoğan N, Ertaş NM, Gündeşlioğlu Ö, et al. Elin birinci web aralığı kontraktürlerinin rhomboid flep kullanılarak serbestleştirilmesi. Türk Plastik, Rekonstrüktif ve Estetik Cerrahi Dergisi 2002;10.2:94-7.

10. Fisher J. External oblique fasciocutaneous flap for elbow coverage. Plast Reconstr Surg 1985;75(1):51-61. 